\title{
Preparation of Red Dyes Derived from Diketo-pyrrolo-pyrrole Based Pigment and Their Properties for LCD Color Filters
}

\author{
Se-Hwa Choi, Ga-hye Kil, Na-rim Kim, Chun Yoon, ${ }^{\dagger}$ Jae-Pil Kim, ${ }^{\ddagger}$ and Jae-Hong Choi ${ }^{*}$ \\ Department of Textile System Engineering, Kyungpook National University, Daegu 702-701, Korea \\ *E-mail: jaehong@knu.ac.kr \\ ${ }^{\dagger}$ Department of Chemistry, Sejong University, Seoul 143-747, Korea \\ ${ }^{\ddagger}$ School of Materials Science and Engineering, Seoul National University, Seoul 151-742, Korea \\ Received August 11, 2010, Accepted September 8, 2010
}

Key Words: Diketo-pyrrolo-pyrrole (DPP), Solubility, Thermal stability, Color filter, Chromaticity diagram

Trichromat pigments, such as C. I. Pigment Red 254, C. I. Pigment Green 36 and C. I. Pigment Blue 15:6, have been used for primary colors of LCD color filter utilizing a photolithographic process. ${ }^{1-4}$ In order to reduce the manufacturing cost and simplify the complicated process of fabrication for color filters, an ink-jet printing method can be studied, ${ }^{5-7}$ where thermally stable trichromat dyes are required to replace conventional pigments.

1,4-Diketo-3,6-diphenylpyrrolo[3,4-c]pyrrole and some of its derivatives, simply called diketo-pyrrolo-pyrrole(DPP), represent high-performance red pigments due to their excellent thermal stability and brilliant shades and exhibits exceptional resistance to chemical, heat, light, and weather. ${ }^{8-9}$ Single crystal $\mathrm{X}$-ray structural studies ${ }^{10-12}$ on DPP indicated that the intermolecular hydrogen bonds between the $\mathrm{NH}$ group of one molecule and the $\mathrm{O}$ atom of the neighboring one contribute high thermal stability and solvent resistance.

A qualitative inspection of 3,6-diaryl-substitued diketo-pyrrolo-pyrroles reveals several reactive centers. ${ }^{13}$ Appropriately substituted phenyl rings should be capable of undergoing electrophilic and nucleophilic aromatic substitutions, and the bicyclic chromophore unit incorporates three different functional groups, namely $\mathrm{C}=\mathrm{C}$ bonds, $\mathrm{C}=\mathrm{O}$ groups, and $\mathrm{NH}$ groups, each amenable to chemical transformation.

In the previous study, ${ }^{14}$ the authors reported that 10 new dyes with $\mathrm{C}_{2}-\mathrm{C}_{9} \mathrm{~N}$-alkyl functions in the DPP ring have been prepared by $N$-alkylation. The thermal stability of the dyes can be highly contributed by both the carbon number and their shapes of $N$-alkyl groups in DPP ring, in particular the dyes substituted by a normal $\mathrm{C}_{8}$ or $\mathrm{C}_{9}$ alkyl group exhibited extremely high stability. However, absorption maxima of the synthesized dyes shifted to shorter wavelength than those of C. I. Pigment Red 254.

To obtain the appropriate absorption maxima of the red dyes which should be similar to that of C. I. Pigment Red 254, in this study, four red dyes containing an $N$-alkyl or $N$-acyl group in the DPP ring were further synthesized, as shown in Figure 1. The effects of $N$-substituent in the DPP ring on the absorption maxima were also studied. Stronger electron withdrawing group $(-\mathrm{CN})$ was introduced at the $p$-position on the phenyl ring replacing the chloro atom to exhibit a red shift. The structures of

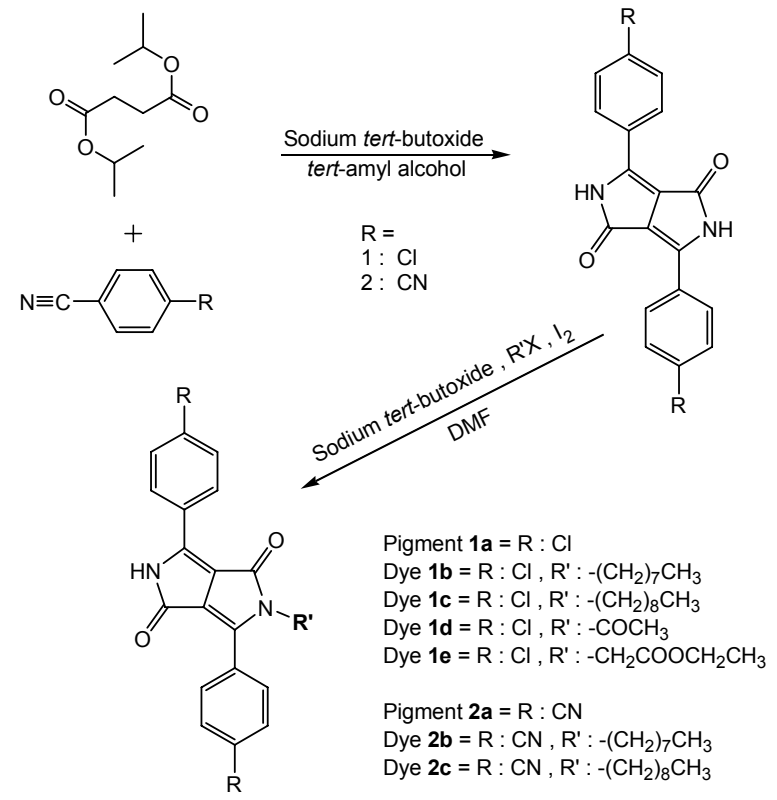

Figure 1. Synthetic scheme of the red dyes.

these dyes were characterized using an elemental analysis and mass spectrophotometer. Absorption maximum $\left(\lambda_{\max }\right)$ and thermal stability of the synthesized dyes were analyzed using by a UV-vis spectrophotometer and thermogravimetric analysis (TGA), respectively. The chromatic characteristics of the fabricated film with the red dyes prepared were analyzed by a spectrometer.

The absorption maxima, chromatic data and transmittance values of C. I. Pigment Red 254 (1a) and synthesized dyes $(\mathbf{1 b}-\mathbf{2 c})$ are summarized in Table 1. Absorption maxima $\left(\lambda_{\max }\right)$ of dyes $1 \mathbf{b}$ and $1 \mathbf{c}$ were measured to be $504 \mathrm{~nm}$ in 1-methyl-2pyrrolidone which were hypsochromic shifts $(12 \mathrm{~nm})$ to that of C. I. Pigment Red 254. A hypsochromic shift observed with dyes $\mathbf{1 b}$ and $\mathbf{1 c}$ can be best explained by the decrease of planarity and conjugation between DPP ring and adjacent phenyl group caused by the introduction of alkyl group. ${ }^{15}$ The dyes $\mathbf{1 d}$ and $\mathbf{1 e}$ substituted with an electron withdrawing group in the DPP ring also exerted a hypsochromic shift that maximally absorbed at 
Table 1. Absorption maxima $\left(\lambda_{\max }\right)$, chromaticity diagram $(x, y)$ and transmittance $(\%)$ of the synthesized dyes $\mathbf{1 b}-\mathbf{2} \mathbf{c}$

\begin{tabular}{ccccc}
\hline & & \multicolumn{2}{c}{$\begin{array}{c}\text { Chromaticity } \\
\text { diagram }\end{array}$} & $\begin{array}{c}\text { Transmittance } \\
(\%, \text { at } 630 \mathrm{~nm})\end{array}$ \\
\cline { 3 - 4 } & & \multicolumn{2}{c}{$\begin{array}{c}\lambda_{\max } \\
(\mathrm{nm})\end{array}$} & \multicolumn{2}{c}{$\mathrm{y}$} & \\
\cline { 3 - 5 } 1a & & & & \\
(C.I. Pigment Red 254) & 516 & 0.577 & 0.336 & 98.9 \\
$\mathbf{1 b}$ & 504 & 0.539 & 0.448 & 99.9 \\
$\mathbf{1 c}$ & 504 & 0.565 & 0.452 & 100 \\
$\mathbf{1 d}$ & 461 & 0.403 & 0.434 & 100 \\
$\mathbf{1 e}$ & 470 & 0.398 & 0.455 & 99.8 \\
$\mathbf{2 b}$ & 524 & 0.538 & 0.351 & 100 \\
$\mathbf{2 c}$ & 525 & 0.552 & 0.356 & 99.9 \\
\hline
\end{tabular}

Determined in $N$-methyl-2-pyrrolidone (NMP)

$461 \mathrm{~nm}$ and $470 \mathrm{~nm}$, respectively, which were in the range of $55 \sim 46 \mathrm{~nm}$ shift in comparison with that of $N$-unsubstituted analogue (C. I. Pigment Red 254). This great blue shift can be attributable to the inductive effect arisen from electron withdrawing groups (acyl group) led to the destabilized excited state. In this case, both effects of the decrease of planarity and conjugation, which was observed with dyes $\mathbf{1 b}$ and $\mathbf{1 c}$, and inductive effect resulting in destabilized excited state occurred simultaneously. However smaller shift was found in $\lambda_{\max }$ of dye 1e due to weak electron withdrawing power of $N$-substituent $\left(-\mathrm{CH}_{2} \mathrm{CO}_{2} \mathrm{Et}\right)$ compared to that of corresponding dye 1d. Dyes $\mathbf{2 b}$ and 2c substituted with an alkyl group in the DPP ring and a $\mathrm{CN}$ group at the $p$-position of phenyl ring exhibited absorption maxima at $524 \mathrm{~nm}$ and $525 \mathrm{~nm}$, respectively, which shifted to longer wavelength of $20 \sim 21 \mathrm{~nm}$ in comparison with those of chloro analogues $\mathbf{1 b}$ and 1c. Smaller shifts were observed when compared with that of C. I. Pigment Red 254 which were 8 and $9 \mathrm{~nm}$, respectively, indicating a substituent at $p$-position of phenyl ring works as an acceptor.

The presumable role of electron withdrawing group for hypsochromic shift by an $N$-substituent and bathochromic shift by substituent at $p$-position of phenyl ring can be calculated using a PPP-MO method, as shown in Figure 2. Electron density

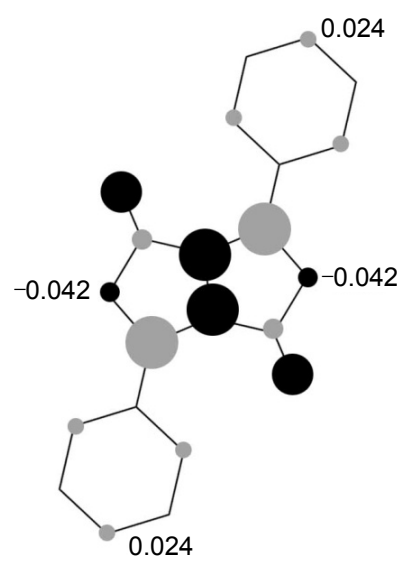

Figure 2. Electron density alteration of red dyes $\mathbf{1 b}, \mathbf{1 c}, \mathbf{2 b}$ and $\mathbf{2 c}$ on excitation into singlet state.
Table 2. Comparison of absorption maxima of dyes $\mathbf{1} \mathbf{a}$ and $\mathbf{2} \mathbf{b}$ between calculated by a PPP-MO method and observed

\begin{tabular}{cccc}
\hline Dye number. & $\mathrm{R}$ & $\lambda_{\max }(\mathrm{nm})^{\text {cal. }}$ & $\lambda_{\max }(\mathrm{nm})^{\text {obs. }}$ \\
\hline 1a & $\mathrm{Cl}$ & 521 & 516 \\
2b & $\mathrm{CN}$ & 558 & 524 \\
\hline
\end{tabular}

alteration on excited state of DPP system indicated that electron density at $p$-position of phenyl ring increases, whereas that of nitrogen atom in the DPP ring decreases. Therefore, it can be explained that the introduction of a $\mathrm{CN}$ group, that is more conjugated in $\pi$-systems and can accommodate efficiently the electrons than chloro group, at $p$-position of phenyl ring readily stabilizes the excited state leading to a bathochromic shift as observed. Conversely, the $N$-substitution of an electron withdrawing group, such as acyl group, in the DPP ring causes the destabilizing effect on the excited state resulting in a hypsochromic shift.

Both the absorption maxima of dyes $\mathbf{1 a}$ and $\mathbf{2 b}$ by a PPP-MO calculation and observed in NMP were summarized in Table 2. The calculation more exactly matched for dye 1a, where calculated $\lambda_{\max }$ was $521 \mathrm{~nm}$ and observed absorption was $516 \mathrm{~nm}$. Larger difference was observed with dye containing a $\mathrm{CN}$ group at $p$-position of phenyl ring which can be explained that the PPP-MO method was originally constructed for the planar $\pi$ conjugated system, therefore it is not appropriate to apply for non-planar molecules ( $N$-substituted dyes). ${ }^{16}$

As indicated in Table 1, the chromaticity diagram of all synthesized dyes exhibited lower $\mathrm{x}$ values and higher $\mathrm{y}$ values than that of C. I. Pigment Red 254 (1a). But the chromaticity diagram of dye $\mathbf{2 b}$ and dye $\mathbf{2} \mathbf{c}$ showed comparatively closer y values to that of C. I. Pigment Red 254 than other dyes. It was also found that x values of dyes containing an $\mathrm{N}$-alkyl group were higher than that of $N$-acyl analogues. A same trend was found in $\mathrm{x}$ values of dyes $\mathbf{2 b}$ and $\mathbf{2 c}$. Comparing the y values between chloro substituted dyes and $\mathrm{CN}$ analogues, quite lower values were observed with dyes $\mathbf{2 b}$ and $\mathbf{2 c}$, but very similar $\mathbf{x}$ values were obtained. Therefore, it can be concluded that, in this series, dye $\mathbf{2 c}$ features in similar color to conventional red pigment $\mathbf{1 a}$.

In terms of transmittance at $630 \mathrm{~nm}$ for synthesized dyes, all materials exhibited over $99.8 \%$ up to $100 \%$ which indicated a more efficient transmittance of red light in comparison with C. I. Pigment Red 254. In case of color filter, transmittance of the light greatly contributes the contrast ratio and brightness of the LCD panel, therefore more efficient performance exerted by the dyes prepared could be a highly valuable property.

Thermal stability of the colorants used for the fabrication of color filters should be required to fulfill the post baking process which is generally carried out at $220^{\circ} \mathrm{C}$, therefore the weight reduction of the colorant should be as small as possible at 200 $250{ }^{\circ} \mathrm{C}$ by TGA. ${ }^{17,18}$ As shown in Table 3 , weight reduction of C. I. Pigment Red 254 was $0.69 \%$ at $250{ }^{\circ} \mathrm{C}$, whereas synthesized dye $1 \mathbf{b}-\mathbf{2 c}$ reduced in the range of $0.01 \sim 17.18 \%$ at the same temperature. The least stability was observed with dye 1d containing an $\mathrm{N}$-acyl group which can be attributable to the lower bond dissociation energy of acyl group than that of alkyl groups. Similarly, dye $1 \mathrm{e} N$-substituted by an $-\mathrm{CH}_{2} \mathrm{CO}_{2}$ Et group also showed comparatively low stability, however the weight 
Table 3. Weight reduction of C.I. Pigment Red 254 and dyes prepared at different temperature measured by TGA and color difference $\left(\Delta \mathrm{E}_{\mathrm{ab}}\right)$

\begin{tabular}{cccc}
\hline \multirow{2}{*}{ Dye number } & $\Delta \mathrm{E}_{\mathrm{ab}}$ & \multicolumn{2}{c}{ Weight (\%) } \\
\cline { 3 - 4 } & & $200{ }^{\circ} \mathrm{C}$ & $250{ }^{\circ} \mathrm{C}$ \\
\hline 1a & - & 99.51 & 99.31 \\
(C.I. Pigment Red 254) & & & \\
$\mathbf{1 b}$ & 7.7 & 99.99 & 99.99 \\
$\mathbf{1 c}$ & 6.3 & 99.85 & 99.66 \\
$\mathbf{1 d}$ & 2.8 & 93.36 & 82.82 \\
$\mathbf{1 e}$ & 3.1 & 96.94 & 95.22 \\
$\mathbf{2 b}$ & 2.6 & 99.12 & 97.72 \\
$\mathbf{2 c}$ & 2.9 & 99.32 & 99.12 \\
\hline
\end{tabular}

Table 4. Solubility of synthesized dyes

\begin{tabular}{ccc}
\hline \multirow{2}{*}{ Dye number } & \multicolumn{2}{c}{ Solubility $(\mathrm{g} / 100 \mathrm{~mL})$} \\
\cline { 2 - 3 } & THF & NMP \\
\hline $\mathbf{1 b}$ & 7 & 9 \\
$\mathbf{1 c}$ & 8 & 10 \\
$\mathbf{1 d}$ & 11 & 12 \\
$\mathbf{1 e}$ & 10 & 11 \\
$\mathbf{2 b}$ & 11 & 13 \\
$\mathbf{2 c}$ & 13 & 14 \\
\hline
\end{tabular}

reduced only $4.78 \%$ indicating a poor thermal stability of the acy group that directly bonded to nitrogen atom in the DPP system. It was observed that dyes $\mathbf{1 b}$ and $\mathbf{1} \mathbf{c}$ tended to be more resistant to heat in comparison with corresponding dyes $\mathbf{2} \mathbf{b}$ and 2c, which may be correlated to smaller chloro atom forming shorter bond distance than that of $\mathrm{CN}$ group. However all dyes containing an $\mathrm{N}$-alkyl group exhibited excellent thermal stability at $250{ }^{\circ} \mathrm{C}$ which seems to be competent to C. I. Pigment Red 254.

The color difference $\left(\Delta \mathrm{E}_{\mathrm{ab}}\right)$ of synthesized dyes was measured after fabrication using a binder then treated at $250{ }^{\circ} \mathrm{C}$ for 60 min. As shown in Table 3, dyes $\mathbf{1 b}$ and $\mathbf{1 c}$ most deviated in $\Delta \mathrm{E}_{\mathrm{ab}}$ value after heat treatment compared to that of dyes $\mathbf{1 d}, \mathbf{1 e}, \mathbf{2 b}$, 2c which was 7.7 and 6.3, respectively. Considering the maximum allowance of $\Delta \mathrm{E}_{\mathrm{ab}}$ value at $250{ }^{\circ} \mathrm{C}$ is 3.0 , other dyes $\mathbf{1 d}$, $\mathbf{2 b}$ and $\mathbf{2 c}$ can be used as a thermally stable red component replacing the conventional red pigment, as $\Delta \mathrm{E}_{\mathrm{ab}}$ value exhibited less than 3.0. However, for dyes $\mathbf{1 b}, \mathbf{1 c}$ and $\mathbf{1 d}$, the order of stability in $\Delta \mathrm{E}_{\mathrm{ab}}$ value conversed with TGA analysis, which can be assumed most likely by the effect of the monomer included in the binder solution. Therefore, in commercial study, the compatibility of dyes with other additives in photo-resist mixture should be optimized by a trial error.

Solubility in THF was determined as $10 \sim 13 \mathrm{~g} / 100 \mathrm{~mL}$ for dyes $\mathbf{1 d}, \mathbf{1 e}, \mathbf{2 b}$ and $\mathbf{2 c}$, but other dyes dissolved in smaller amount of $7 \sim 8 \mathrm{~g} / 100 \mathrm{~mL}$. The results in NMP were very similar to THF, thus for the same dyes the solubility showed $11 \sim 14 \mathrm{~g} /$ $100 \mathrm{~mL}$. It is generally required that dyes should be dissolved in an appropriate solvent at least $10 \mathrm{~g} / 100 \mathrm{~mL}$ for ink-jet printing fabrication. Therefore, dyes $\mathbf{1 d}, \mathbf{1 e}, \mathbf{2 b}$ and $\mathbf{2 c}$ could be proper material to manufacture red ink. Results of solubility test in THF and NMP were shown in Table 4.
As reported in the previous study, ${ }^{14}$ introduction of an $N$-alkyl group into the DPP ring resulted in a hypsochromic shift around $15 \mathrm{~nm}$. In this study, the authors can conclude that substitutions by an $N$-acyl group also exerted a hypsochromic shift of more than $46 \mathrm{~nm}$ depending on the place of acyl group which can be explained by both the inductive effect arisen from electron withdrawing groups and the decrease of planarity and conjugation between DPP ring and adjacent phenyl group. However, the replacement of chloro in the $p$-position of phenyl ring by a $\mathrm{CN}$ group, which is stronger electron withdrawing group, combining with an $N$-alkylation exhibited very similar absorption maxima to that of corresponding red pigment. In terms of chromaticity diagram, the colors of all dyes prepared were yellower than $\mathrm{C}$. I. Pigment Red 254, two dyes containing a CN group at the $p$-position of phenyl ring showed closer values. As expected, all dyes exerted high transmittance at $630 \mathrm{~nm}$ which was more than $99.8 \%$.

Thermal stability of dyes $\mathbf{2 b}$ and $\mathbf{2 c}$ revealed to be equivalent to the red pigment by both methods of TGA and $\Delta \mathrm{E}_{\mathrm{ab}}$ value. However, dyes containing an $N$-acyl group tended to be poor in TGA analysis due to the low bond dissociation energy.

Solubility in THF and NMP was determined as more than $10 \mathrm{~g} / 100 \mathrm{~mL}$ for dyes $\mathbf{1 d}, \mathbf{1 e}, \mathbf{2 b}$ and $\mathbf{2 c}$, which seems to be capable of adaption of ink-jet printing replacing the complicated lithographic method for color filter fabrication.

Therefore, these dyes prepared could be used as an alternative component for conventional red pigment to increase the contrast ratio and brightness which are crucial requirements in LCD color filter sector.

\section{Experimental Section}

2-Acetyl-3,6-bis(4-chlorophenyl)pymolo[3,4-c]pymole-1,4 (2H,5H)-dione (dye 1d). Under nitrogen condition, 3,6-bis(4chlorophenyl)pyrrolo[3,4-c]pyrrole-1,4(2H,5H)-dione (3.56 g, $0.01 \mathrm{~mol})$ and sodium tert-butoxide $(2.88 \mathrm{~g}, 0.03 \mathrm{~mol})$ were dissolved in DMF (150 mL) and stirred for $1 \mathrm{hr}$ at room temperature, then triethylamine $(1 \mathrm{~g}, 0.01 \mathrm{~mol})$, acetyl chloride $(1.2 \mathrm{~g}$, $0.015 \mathrm{~mol})$ and $\mathrm{I}_{2}(0.2 \mathrm{~g}, 0.001 \mathrm{~mol})$ were added. The mixture was heated to $60^{\circ} \mathrm{C}$, further stirred for $15 \mathrm{hrs}$ at the same temperature with regular checking by TLC (stationary phase : silica gel, mobile phase : $n$-hexane/EtOAc $=2 / 1)$. When the reaction completed, cooled to room temperature, then ethyl acetate (150 $\mathrm{mL})$ and water $(200 \mathrm{~mL})$ were added. The ethyl acetate layer was separated from the aqueous layer, followed by drying with $\mathrm{MgSO}_{4}$, anh. (around $10 \mathrm{~g}$ ) and filtered. Evaporation of the ethyl acetate gave a mixture of mono- and di-substituted products. Subsequent isolation of mono-substituted component (1d) was carried out by adding the crude product to a mixture of $n$-hexane $(30 \mathrm{~mL})$ and chloroform $(3 \mathrm{~mL})$. After stirring for a further 5 minutes at the same condition, the precipitated solid was filtered and subsequently washed with a mixture of $n$-hexane $(10 \mathrm{~mL})$ and chloroform $(3 \mathrm{~mL})$. The filtered solid was dried under a vacuum to obtain dye 1 d in $27 \%$ yield. $\mathrm{C}_{20} \mathrm{H}_{12} \mathrm{Cl}_{2} \mathrm{~N}_{2} \mathrm{O}_{3}$, Found C, 60.78; H, 3.12; N, 6.89; O, 12.15. Calculated C, 60.17; H, 3.03; N, 7.02; O, 12.02. MS (m/z) $398(\mathrm{M}+)$.

Other dyes were obtained by same procedure except reaction temperature $\left(40{ }^{\circ} \mathrm{C}\right.$ for dye $1 \mathrm{e}, 75^{\circ} \mathrm{C}$ for dyes $\mathbf{2 b}$ and $\left.\mathbf{2 c}\right)$. 
Dye $1 \mathbf{b} \&$ Dye 1c : previously reported in reference 14 .

Dye 1e Yield : $36 \%$, Found C, 60.24; H, 3.41; N, 6.45; O, 14.22, Calculated $\mathrm{C}_{22} \mathrm{H}_{16} \mathrm{Cl}_{2} \mathrm{~N}_{2} \mathrm{O}_{4} \mathrm{C}, 59.61 ; \mathrm{H}, 3.64 ; \mathrm{N}, 6.32$; $\mathrm{O}, 14.44$, MS $442(\mathrm{M}+)$

Dye 2 b Yield : 26\%, Found C, 74.12; H, 5.64; N, 12.78; O, 7.29, Calculated $\mathrm{C}_{28} \mathrm{H}_{26} \mathrm{~N}_{4} \mathrm{O}_{2} \mathrm{C}, 74.65 ; \mathrm{H}, 5.82 ; \mathrm{N}, 12.44 ; \mathrm{O}$, 7.11, MS $450(\mathrm{M}+)$

Dye 2c Yield : 24\%, Found C, 74.25; H, 6.42; N, 12.01; O, 7.04, Calculated $\mathrm{C}_{29} \mathrm{H}_{28} \mathrm{~N}_{4} \mathrm{O}_{2} \mathrm{C}, 74.98 ; \mathrm{H}, 6.08 ; \mathrm{N}, 12.06 ; \mathrm{O}$, 6.89 , MS $464(\mathrm{M}+)$

Fabrication of color filter. In order to measure optical characteristics and thermal stability, spin-coating was carried out onto glass using a MIDAS System SPIN-1200D spin coater. The glass was spun at a low to moderate speed of $300 \mathrm{rpm}$ for $10 \mathrm{sec}$ to evenly spread the solution. The solution was prepared with synthesized dyes, solvent (1-methyl-2-pyrrolidone) and binder based on acrylate polymer. Once spin-coating was completed, the film was placed quickly onto a hot plate (heated to somewhere around $100^{\circ} \mathrm{C}$ ) for $5 \mathrm{~min}$ to evaporate the solvent.

Thermal stability of color filter. Thermal stability of synthesized dyes after fabrication was measured by a prebaking at $220{ }^{\circ} \mathrm{C}$ for $30 \mathrm{~min}$ then by a post-baking at $250{ }^{\circ} \mathrm{C}$ for $60 \mathrm{~min}$, thereafter color difference in $\Delta \mathrm{E}_{\mathrm{ab}}$ was measured.

Solubility test. The synthesized dyes added into tetrahydrofuran (or NMP, $20 \mathrm{~mL}$ ) then stirred at room temperature for 30 mins. The supersaturated solution was passed $0.45 \mu \mathrm{m}$ syringe filter. Filtered solid not passed was dried at $65^{\circ} \mathrm{C}$ then weighed to calculate the dissolved weight of dye.

PPP-MO. The PPP-MO method was used to calculate the excitation energy of $\pi$ electrons between HOMO and LUMO using PISYSTEM ${ }^{\circledR}$ Version 6.2.

Acknowledgments. This research was supported by a grant from the Fundamental R\&D Program for Core Technology of
Materials funded by the Ministry of Knowledge Economy, Republic of Korea.

\section{References}

1. Ichimura, K. Advanced Technologies for LCD Color Filters; CMC Publishing: Tokyo, Japan, 2006; p 8.

2. Takahashi, T. J. Imag. Soc. Japan 2002, 41, 68.

3. Sugiura, T. J. Print. Sci. Tech. Japan 1996, 356.

4. Carr, K. Colorants for Non-Textile Applications; Freeman, H. S., Peters, A. T., Eds.; Elsevier: London, U. K., 2000; pp 28-29.

5. Hao, Z.; Iqbal, A. Chem. Soc. Rev. 1997, 26, 203-213 and references therein.

6. Mizuguchi, J.; Grubenmann, A.; Wooden, G.; Rihs, G. Acta Crystallogr. 1992, B48, 696-700.

7. Zollinger, H. Color Chemistry, Syntheses, Properties, and Applications of Organic Dyes and Pigments; Wiley-VCH: Weinheim, Germany, 2003; pp 336-339.

8. Zollinger, H. Color Chemistry, Syntheses, Properties, and Applications of Organic Dyes and Pigments; Wiley-VCH: Weinheim, Germany, 2003; p 331.

9. Iqbal, A.; Cassar, L.; Rochat, A. C.; Pfenninger, L.; Wallquist, O. J. Coating Technol. 1988, 60, 37.

10. Iqbal, A.; Kirchmayr, R.; Rochat, A. C.; Pfenninger, L.; Wallquist, O. Bull. Soc. Chim. Belg. 1988, 97, 615.

11. Iqbal, A.; Medinger, B.; Mckay, R. B. Physico-Chemical Principles of Color Chemistry; Peters, A. T., Freeman, H. S., Eds.; Blackie Academic \& Professional: London, U. K., 1996; p 116.

12. Mizuguchi, J.; Rihs, G. Ber. Bunsenges. Phys. Chem. 1992, 96(4), 597.

13. Glaser, F. Industrial Organic Pigments; Herbst, W., Hunger, K., Eds.; VCH: Weinheim, Germany, 1993; p 50.

14. Choi, S. H.; Kwon, O. T.; Kim, N. R.; Yoon, C.; Kim, J. P.; Choi, J. H. Bull. Korean Chem. Soc. 2010, 31(4), 1073.

15. Martin, V.; Martin, W.; Jan, V.; Petr, T.; Stanislav, L. J. Fluoresc. 2008, 18,1185

16. Masafumi A.; Shinichiro, N. J.Phys. Chem. 1994, 98, 1796-1801.

17. Das, S.; Basu, R.; Minch, M.; Nandy, P. Dyes \& Pigments 1995, 29, 191-201.

18. Chunlong, Z.; Nianchun, M.; Liyun, L. Dyes \& Pigments 1993, 23 , 13-23. 